\title{
A Numerical and Experimental Investigation of Simulated Explosions Inside a Flow Network
}




\section{DISCLAIMER}

This report was prepared as an account of work sponsored by an agency of the United States Government. Neither the United States Government nor any agency Thereof, nor any of their employees, makes any warranty, express or implied, or assumes any legal liability or responsibility for the accuracy, completeness, or usefulness of any information, apparatus, product, or process disclosed, or represents that its use would not infringe privately owned rights. Reference herein to any specific commercial product, process, or service by trade name, trademark, manufacturer, or otherwise does not necessarily constitute or imply its endorsement, recommendation, or favoring by the United States Government or any agency thereof. The views and opinions of authors expressed herein do not necessarily state or reflect those of the United States Government or any agency thereof. 


\section{DISCLAIMER}

Portions of this document may be illegible in electronic image products. Images are produced from the best available original document. 
This work was supported by the US Department of Energy, Office of Nuclear Safety, Division of Nuclear Facility Safety.

This report was prepared as an account of work sponsored by an agency of the United States Government. Neither the United States Government nor any agency thereof, nor any of their employees, makes any warranty, express or implied, or assumes any legal liability or responsibility for the accuracy, completeness, or usefulness of any information, apparatus, product, or process disclosed, or represents that its use would not infringe privately owned rights. References herein to any specific commercial product, process, or service by trade name, trademark, manufacturer, or otherwise, does not necessarily constitute or imply its endorsement, recommendation, or favoring by the United States Government or any agency thereof. The views and opinions of authors expressed herein do not necessarily state or reflect those of the United States Government or any agency thereof. 


\section{$\left(\begin{array}{c}\text { LA--9340-HS } \\ \text { DE82 } 016243 \\ .\end{array}\right.$ \\ A Numerical and Experimental Investigation of Simulated Explosions Inside a Flow Network}

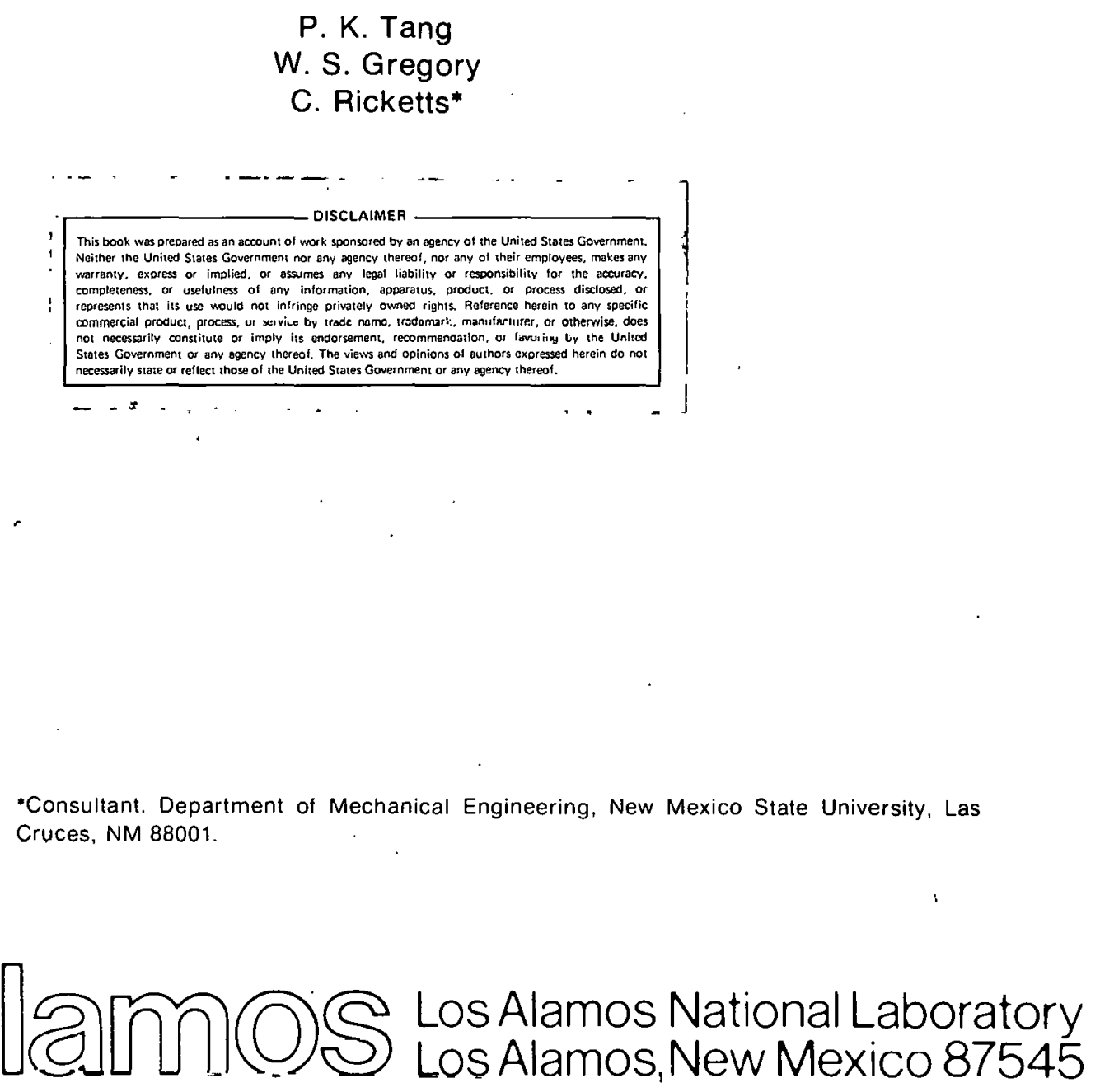




\title{
A NUMERICAL AND EXPERIMENTAL INVESTIGATION OF SIMULATED EXPLOSIONS INSIDE A FLOW NETWORK
}

\section{by}

P. K. Tang, W. S. Gregory, and C. Ricketts

\begin{abstract}
We will present the results of a numerical and an experimental study of a flow network subjected to a simulated explosion. The numerical simulation uses a computer code called EVENT that predicts the response of a system under gas-dynamic stress conditions. The experiment uses a real flow system that is injected with a high-pressure gas. The results from these two are compared using a flow parameter such as pressure. We conclude that the numerical calculation matches the results of the experiment quite well.
\end{abstract}

\section{INTRODUCTION}

An analytical tool that can predict the gas dynamics within a flow network that is subjected to an internal explosion needs to be developed. However, the usefulness of such a tool depends on how much we understand the physics involved in the gas dynamics, how we formulate it into mathematical expressions, how we simplify it so that the problem becomes manageable, and finally, how we obtain the solution numerically. The tool's usefulness should be checked independently by actual experimentation. A carefully conceived experimental program should be constructed within the realm of the analytical limitation but should not excced it. 
We have conducted a series of experiments simulating an explosion in a simple flow network. The network consists of two vessels with a long connecting pipe. One of the vessels is vented to the atmosphere through an orifice of a known size. The same vessel is connected to a high-pressure air supply. system, and the rate of air injection is regulated by an orifice flowmeter. The duration of the venting is controlled by rapidly opening and closing two valves in series. The air injection rate is calculated using an empirical flowmeter relation with measured pressure information. A computer code uses the calculated flow rate as the simulated explosion in the system, and the output of the computer code includes pressures, temperatures, and flow rates at different locations. We measured pressure transients in the two vessels and compared them with the numerical values predicted by the code.

We will describe the analytical aspect of the program only briefly and then discuss the experiment in detail. 'The objectives of this report are (1) to compare the numerical simulation with the experiment based on direct measurement and (2) to prove the adequacy of the analytical approach.

\section{THEORETICAL BASIS}

A computer code called EVENT has been developed at the Los Alamos National Laboratory that is capable of handling severe gas-dynamic transients inside a flow network. The description of the code and its development is detailed elsewhere, ${ }^{1}$ and the use of the code is documented separately.? We will summarize only the important features of the code here.

A flow network is assumed to consist of two major components, nodes and branches. A node can be either a boundary where the atmospheric condition is usually assumed or a room (volume) where the laws of conservation of mass and energy are applied. Branches make the connection between any two nodes, and they can be ducts, filters, or blowers. A duct momentum equation that includes the effects of wall friction and inertia is used to relate the flow rate and the pressure drop; choking is imposed on the duct flow if the condition warrants it. A filter is a resistance element, and both linear and quadratic relations of pressure to the flow rate are included. Finally, a quasi-steady relation is imposed on the pressure head and the flow rate for the blower. This lumped-parameter approach to describe the network system ignores the detailed spatial variation of the flow properties. 
We have discussed already how the gas-dynamic and thermodynamic conservation laws are applied to the network system. We assume further that only air is present, and it follows ideal gas laws. Finally, an explosion is simulated by injecting high-pressure air into the system. The justification.for this approach has been presented elsewhere, ${ }^{1}$ and it forms the basis of the analysis. The solution is carried out numericallý by using the EVENT computer code. Because this is the first in a series of efforts to verify the computer code, we will begin with a relatively simple flow system consisting of rooms and connecting flow paths without the complication of filters and blowers.

\section{EXPERIMENTAL FACILITY}

The experimental apparatus is located at the Los Alamos test facility on the campus of New Mexico State University. The test section includes two steel vessels, $T_{1}$ and $T_{2}$, connected by a long steel pipe, $L$ (Fig. 1 ). Vessel $T_{1}$ is vented to the atmosphere through a square-edged discharge orifice, $0 . \ldots$ The volume of each vessel is $9.8 \mathrm{ft}^{3}\left(0.277 \mathrm{~m}^{3}\right)$, the diameter of the connecting pipe is 2 in. nominal with a 2.067-in. (8.14-mm) inside diameter, and the length of the pipe is $16.17 \mathrm{ft}(4.93 \mathrm{~m})$ or $31.25 \mathrm{ft}(9.52 \mathrm{~m})$. The discharge orifice is made of $3 / 16-i n .(4.76-\mathrm{mm})$-thick aluminum plate. We used diameter sizes of $1 / 2 \mathrm{in.}(12.7 \mathrm{~mm})$ and $1 \mathrm{in} .(25.4 \mathrm{~mm})$. This or ifice is flange-mounted for

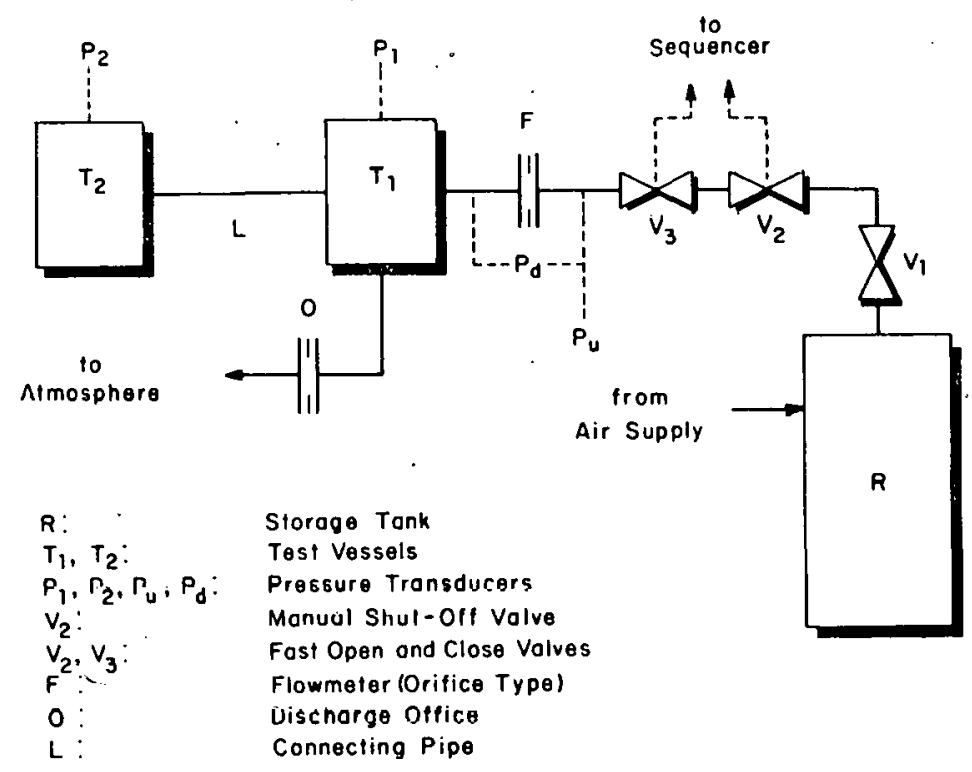

Fig. 1.

Test facility "schematic. 
easy removal, and the connecting pipe is attached to the test vessels with flange couplings as well. The longer one has two $90^{\circ}$ elbows.

A high-pressure air supply system is used to inject air into vessel $T_{1}$ to provide the explosion simulation. A large air storage tank, $R$, is pressurized to $300 \mathrm{psig}$ (2068 kPa gauge) and is connected to vessel $T_{1}$, through a series of valves and a square-edged orifice flowmeter, $F$. This orifice is similar to the discharge orifice, but the flange mounting has pressure taps following the American Society of Mechanical Engineers standard, ${ }^{3}$ and the pipe is $3 \mathrm{in.}(76.2 \mathrm{~mm})$ in diameter. Two fast-acting solenoid control plug valves (Magnatrol), $v_{2}$ and $v_{3}$, are installed upstream of this orifice to control the duration of air injection. One is normally closed, and the other is normally open. A manual shut-off valve is used further upstream to completely isolate the air injection system. The complete system is designed to

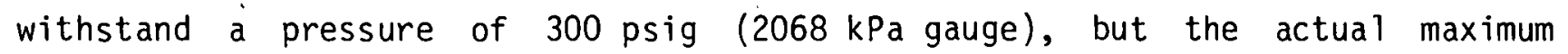

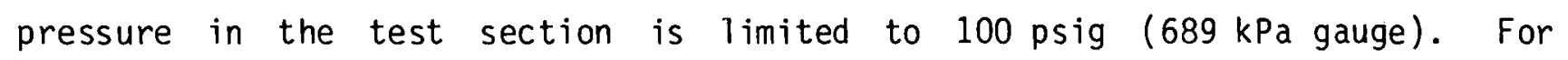
safety reasons, we installed pressure-relief valves on each test vessel with a set point of 125--140 psig ( $862--965 \mathrm{kPa}$ gauge). We will discuss the instrumentation and control in greater detail in Sec. IV.

\section{INSTRUMENTATION AND DATA ACQUISITION}

Four pressure transducers are used in the experiment. $P_{u}$ and $P_{d}$ are used to measure the pressure upstream of the flowmeter and the pressure differential across the orifice plate (Fig. 1). The information obtained from these pressure measurements will be used to calculate the rate of air injection into the test section. $P_{1}$ and $P_{2}$ record the pressure transients in the test vessels. The analytical calculation also will yield similar information under the effect of the simulated explosion. The soundness of the analytical result is judged by how we 11 the numerical simulation predicts the measured transient pressures in the two test vessels. All four pressure transducers are the variable-reluctance type made by Validyne. They have excellent linearity with $P_{u}$ and $P_{d}$ calibrated at $330 \mathrm{psi}(2275 \mathrm{kPa})$. However, the calibration range for $P_{1}$ and $P_{2}$ is $20--70$ psi $(138--483 \mathrm{kPa})$ to maximize the sensitivity for different runs.

Two methods are used to record the pressure transient data. The principal one is a PDP-11 computer that samples the data channels in sequence every $3 \mathrm{~ms}$. An oscillograph chart recorder is used as a separate means of checking. The 4 
digitized data from the computer are compared with the analog data registered on the oscillograph to ensure consistency. Once the data are verified, the digitized result is transferred from a magnetic disk to tape for storage and shipping to Los Alamos. The data are fed into the Los Alamos computers for final processing.

\section{EXPERIMENTAL PROCEDURES}

We used various combinations of pipe length, flowmeter orifice size, discharge orifice size, and air injection duration to achieve different system geometries and pulse intensities and durations. The system geometry and the ambient air condition were recorded for each experiment.

With the shut-off valve closed, the air storage tank is pressurized to approximately $300 \mathrm{psig}$ (2068 kPa gauge), and the air temperature is measured. In the meantime, the pressure recording device is made ready, and the sequencer is set to the desired pulse duration (approximately $1.0,1.5$, or $2.0 \mathrm{~s}$. ) The fastacting valves are set to their normal positions (one open and one closed). The manual shut-off valve is opened just before the run. We then start the recording device and the sequencer. They will open the closed fast-acting valve to a fully open position in approximately $100 \mathrm{ms,}$, which starts air injection. When the desired pulse duration has elapsed, the sequencer will close the open fastacting valve completely in roughly $100 \mathrm{~ms}$ and terminate air injection into the test section. The pressure recording device is allowed to continue up to $10 \mathrm{~s}$ and then stop. The experiment is completed at this point, and the manual shutoff valve should be back in the closed position for safety. Another experimental cycle can bc started soon after the fast-asting valves return to their original positions and the sequencer and the pressure recording device are reset.

During the test, all four pressure readings $\left(P_{1}, P_{2}, P_{d}\right.$, and $\left.P_{u}\right)$ $c$ an be monitored by a strip-chart recorder. The success or failure of each run can be judged from the strip-chart traces as soon as the run is completed. In the meantime, a magnetic recording device is used to register the same information for later use. The final digitized result is fed into the Central Computing Facility at Los Alamos.

As we pointed out earlier, the simulated explosion is generated by an injection of air into the test portion of the apparatus. Therefore, an accurate calculation of the mass injection rate and the associated energy rate is important for input to the EVENT code. For this reason, we employ a semi-empirical 
formulation for a square-edged thin-plate orifice ${ }^{3}$ and extend it into the choking region. Because the formula requires the pressure differential information, the downstream pressure should be replaced under the choking condition by the orifice throat pressure, which is calculated with the adiabatic expansion to sonic condition. Therefore, we have developed a separate code to calculate the flow rate for a given pipe, flowmeter orifice size, storage tank temperature, upstream pressure, and differential pressure across the orifice plate. The last two are functions of time during the air-injection phase.

So far, we have presented only the experimental aspect of the program; the numerical simulation requires modeling the physical system for the computer code properly, and this model is shown in Fig. 2. Nodes 1 and 2 represent the two test vessels; node 3 represents the boundary. The long pipe is designated branch 1, and the discharge orifice is designated branch 2. The geometric description of the system includes volume, pipe length, flow area, and the resistance calculated for the given arrangement with any standard fluid flow handbook. 4 With the initial condition given, we can combine the geometric data and the air injection rate calculated separately to form an input file. Running the EVENT code with the given input is a numerical simulation of the experiment. We are interested in the result of this prediction for the vessel pressure transients, $P_{1}$ and $P_{2}$, and in comparison to the actual measurements. Examples are presented below.

\section{RESULTS AND DISCUSSION}

Figures $3--9$ present results of both experiments and numerical simulations. For each run, the same condition and compatible air injection rate are imposed. The markers are from the experimental measurement, and the continuous curves represent the numerical (EVENT) calculation. The geometry for the first three cases (Figs. 3 to 5 ) is identical to both flowmeter orifice and discharge orifice at a 1/2-in. (12.7-mm) diameter and a $16.17-\mathrm{ft}(4.93-\mathrm{m})$ pipe length.

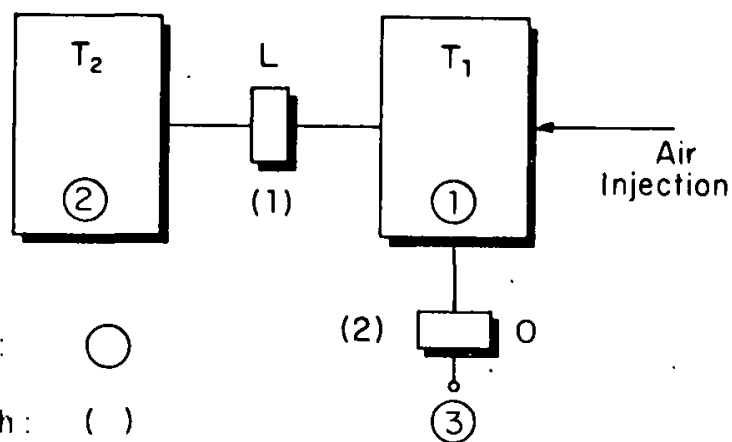

Fig. 2 . EVENT model. 


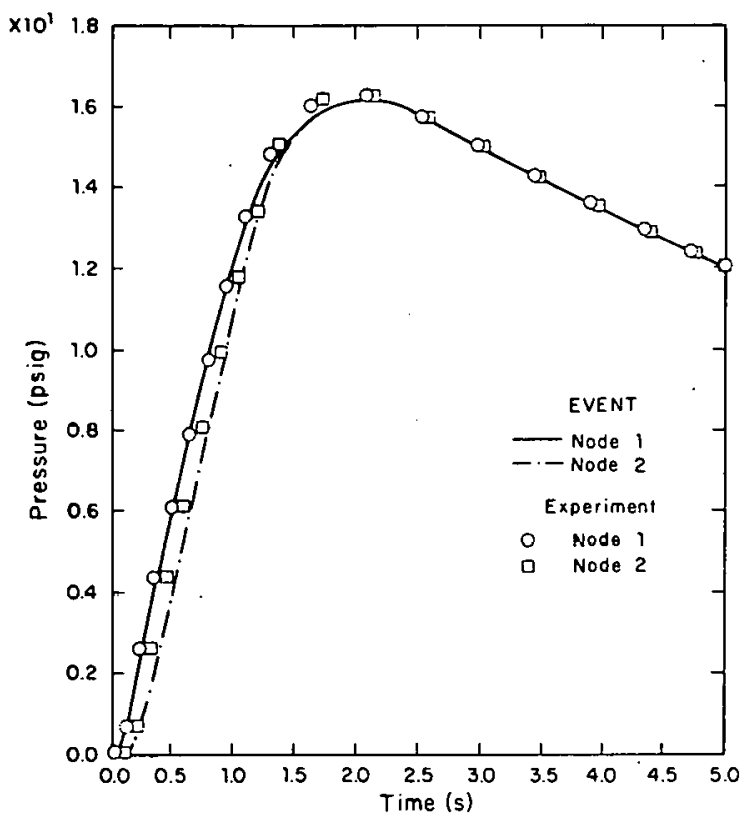

Fig. 3.

Experimental and numerical (EVENT) results for tests using a $16.17-\mathrm{ft}$ (4.93-m) pipe length, a 0.5-in. $(12.7-\mathrm{mm})$ orifice diameter, and a 1.0-s pulse duration.

Fig. 4 .

Experimental and numerical (EVENT) results for tests using a 16.17-ft (4.93-m) pipe length, a 0.5-in. $(12.7-\mathrm{mm})$ or ifice diameter, and a 1.5-s pulse duration.

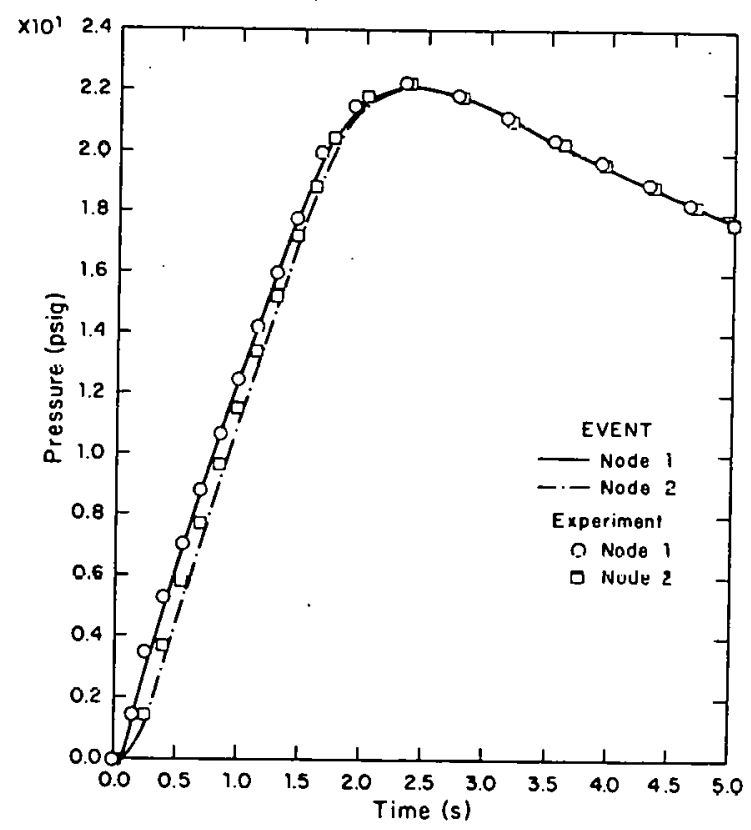




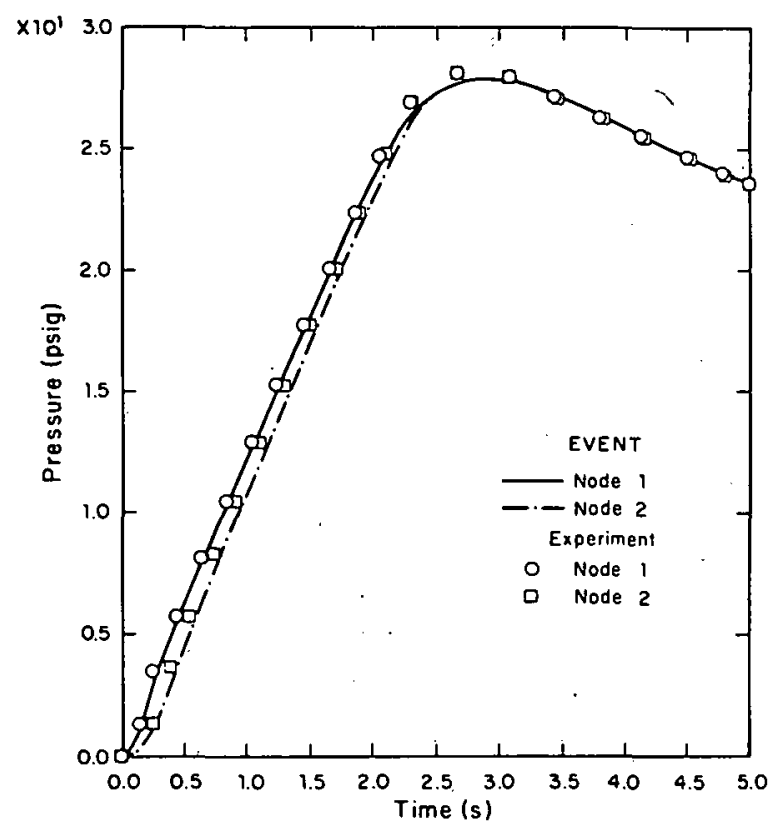

Fig. 5 .

Experimental and numerical (EVENT) results for tests using a 16.17-ft (4.93-m) pipe length, a 0.5-in. $(12.7-\mathrm{mm})$ orifice diameter, and $a$. 2.0-s pulse duration.

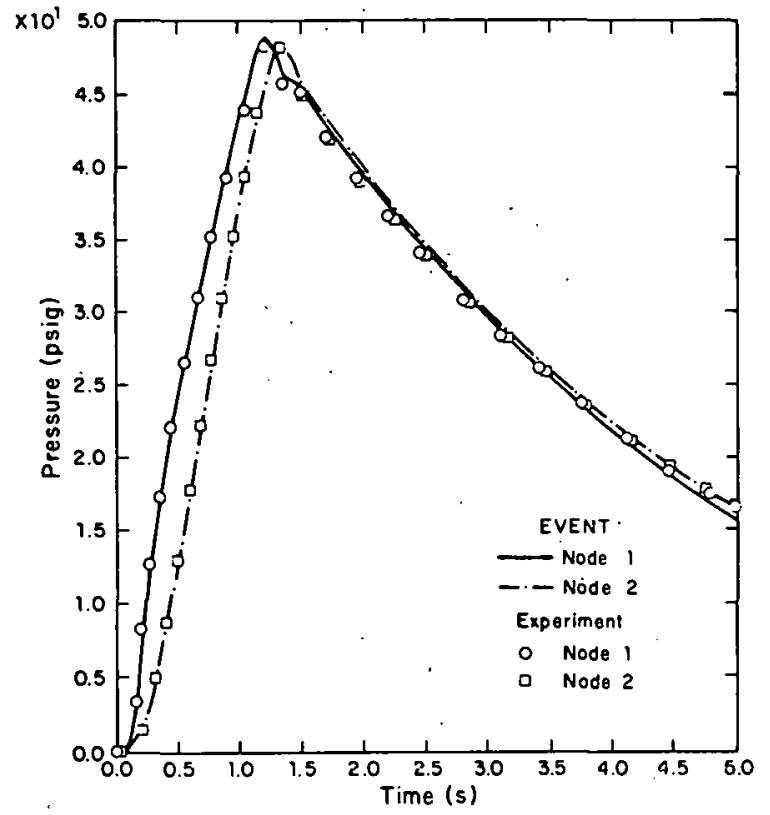

for tests using a $16.17-\mathrm{ft}$ $(4.93-\mathrm{m})$ pipe length, a 1.0-in. $(25.4-\mathrm{mm})$ orifice diameter, and a 1.0-s pulse duration.

Fig. 6 .

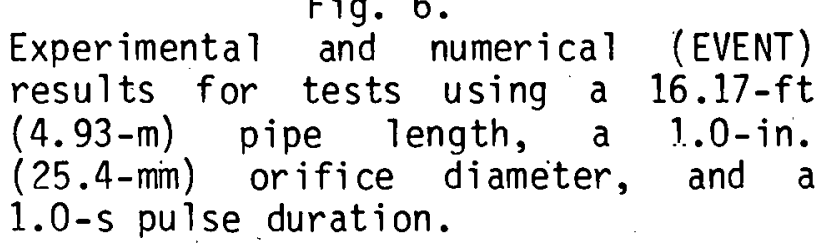




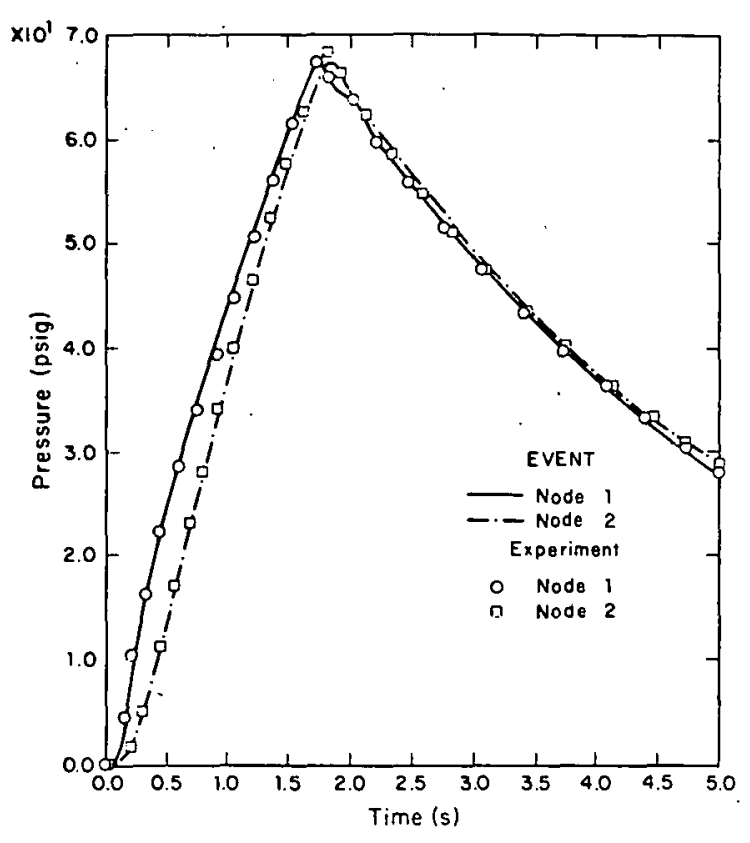

Fig. 8 .

Experimental and numerical (EVENT) results for tests using a.31.25-ft $(9.52-\mathrm{m})$ pipe length, a 1.0-in. (25.4-mm) or ifice diameter, and a $1.0-s$ pulse duration.
Fig. 7.

Experimental and numerical (EVENT) results for tests using a $16.17-\mathrm{ft}$ (4.93-m) pipe length, a 1.0-in. $(25.4-\mathrm{mm})$ orifice diameter, and a 1.5-s pulse duration.

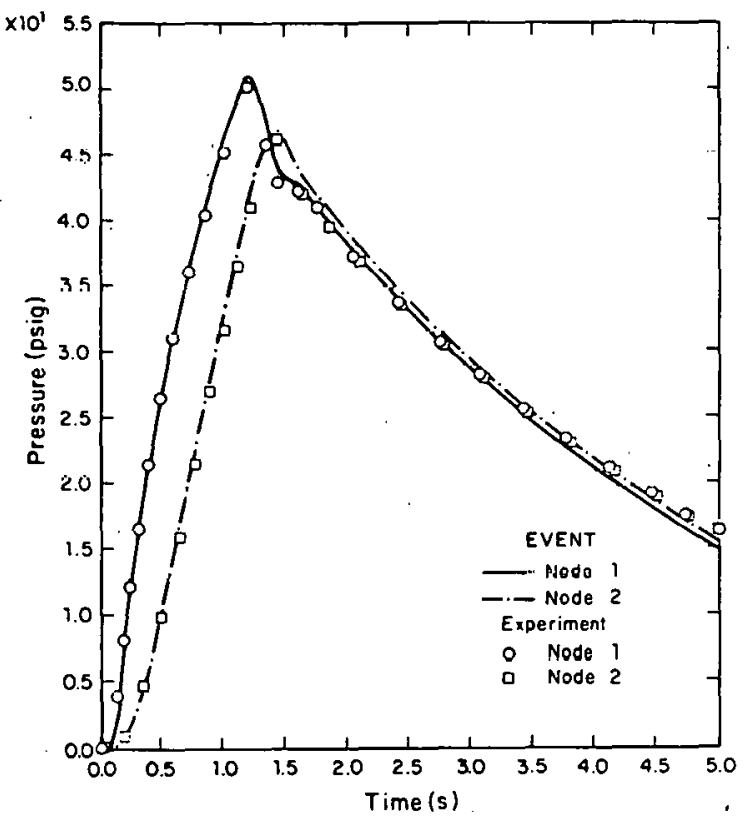




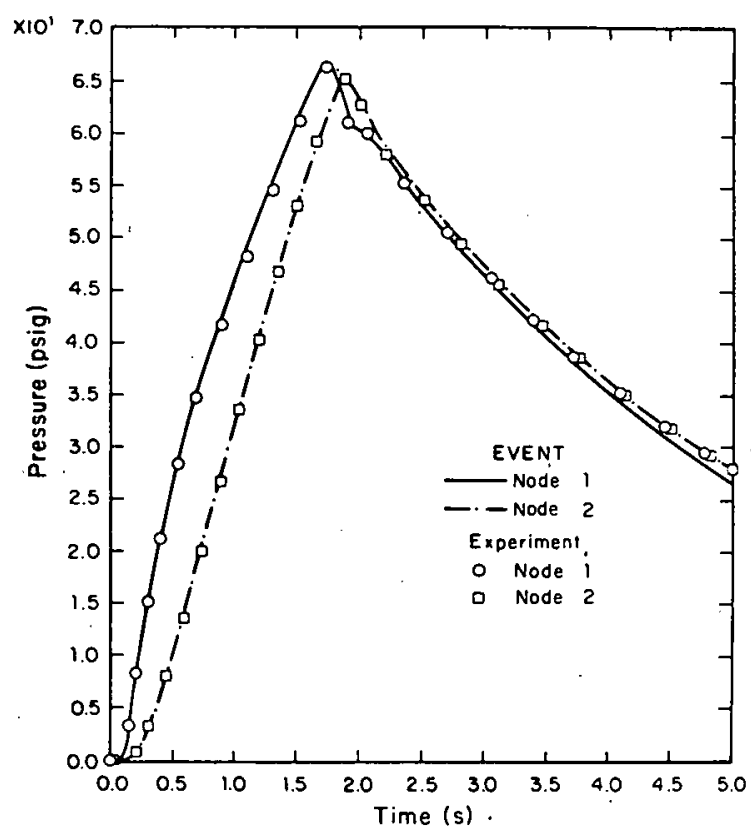

Fig. 9.

Experimental and numerical (EVENT) results for tests using a 31.25-ft (9.52-m) pipe length, a 1.0-in. $(25.4-\mathrm{mm})$ orifice diameter, and a 1.5-s pulse duration.

The initial condition is similar, but the major difference is the air injection duration, which is approximately $1.0 \mathrm{~s}$ in Fig. 3, $1.5 \mathrm{~s}$ in Fig. 4, and $2.0 \mathrm{~s}$ in Fig. 5. We can see the peak pressures are higher and occur later for a longer pulse, The numerical prediction corresponds to the experimental measurement quite well. Figures 6 and 7 show the results of 1 arger flowmeter and discharge orifice size, both at a $1-i n .(25.4-\mathrm{mm})$ diameter. The pipe length remains the same as in the previous three cases. The air injection duration is roughly $1.0 \mathrm{~s}$ (Fig. 6) and $1.5 \mathrm{~s} \mathrm{(Fig.} \mathrm{7).} \mathrm{The} \mathrm{larger} \mathrm{flowmeter} \mathrm{gives} \mathrm{a} \mathrm{faster} \mathrm{pres-}$ sure rise rate and a higher peak value, but the larger discharge orifice provides a more rapid pressure relief. These trends are evident when Figs. 6 and 7 are compared with the previous three figures. Also notice how accurately the numerical result simulates the behavior of the experiment near the peak region.

Finally, we increased the pipe length to $31.25 \mathrm{ft}(9.52 \mathrm{~m})$ to enhance the effects of inertia and resistance for that branch. Figures 8 and 9 show the results of simulations using air injection durations of approximately 1 's and $1.5 \mathrm{~s}$. Comparing these results with Figs. 6 and 7 , we see that the pressure difference between nodes 1 and 2 is larger in the earlier phase of the transient. Because the pipe has more resistance, the additional inertia will also contribute to the increase. The best indication of larger inertia for a longer pipe is the longer time lag between the two pressure peaks. Again, there is good agreement between the numerical simulation and experiments. 


\section{CONCLUSION}

We have attempted to demonstrate the capability and validity of the computer code EVENT. With some variation in flowmeter size, discharge orifice size, pipe length, and air injection duration, the computed result simulates the physical measurement accurately. We conclude that we have achieved the goal of constructing a computer code that contains the proper physics and mathematical manipulation and can handle severe gas-dynamic transients inside a flow network that contains the elements presented in this report.

\section{ACKNOWLEDGMENTS}

M. Beckett, H. Grothus, and P. Ricketts designed and performed the experiments discussed: in this report. R. Leep and $R$. Lidh developed the data acquisition system. R. Andrae developed the graphics, and P. Smith supervised the experimental program at New Mexico State University. Their contributions to this program are especially appreciated.

\section{REFERENCES}

1. P. K. Tang, R. W. Andrae, J. W. Bolstad, K. H. Duerre, and W. S. Gregory, "Analysis of Ventilation Systems Subjected to Explosive Transients-Far-Field Analysis," Lọ Alamos National Laboratory report LA-9094-MS (November 1981).

2. R. W. Andrae, P. K. Tang, J. W. Bolstad, and W. S. Gregory, "EVENT Computer Cude Mariual," Los Alamos National Laboratory report in preparation.

3. H. S. Bean, Ed., Fluid Meters, Their Theory and Application (American Society for Mechanical Engineering, New York, 1971).

4. Crane Company Engineering Division, "Flow of Fluids Through Valves, Fittings, and Pipe," Crane Company Technical Paper No. 410 (1969). 


\section{Printed in the United States of America}

Available from

National Tochnical Information Service

US Department of Commerce

5285 Port Royal Road

Springfield, VA 2216

Microfiche (A01)

NTIS

Page Range Price Code

\section{$001-025$}

$026-050$

051.075

076-100

$101-125$

$126-150$

\section{$\mathrm{A} 02$}

A 03

A04

A05

A05
A06
A07

Page Range Price Code

$151-175$

$176-200$

201- 225

226-250

251-275

276-300

A08

A09

A 10

A11

A 13
NTIS

\begin{tabular}{cc} 
Page Range & Price Code \\
\hline $301-325$ & A 14 \\
$326-350$ & A 15 \\
$351-375$ & A 16 \\
$376-400$ & A 17 \\
$401-425$ & A 18 \\
$426-450$ & A 19
\end{tabular}

NTIS

Page Range Price Code

451.475

476-500

$501-525$

$526-550$

A20

A 21

A 22

A23

551-575 A24

$576.600 \quad$ A25

601-up* A99

${ }^{*}$ Contact NTIS for a price quote. 
- 13

LOS Alamos 